\title{
Desmoplastic infantile ganglioglioma: A case report and review of literature
}

\begin{tabular}{ccc}
\hline J alal A. J alal* & Kadamkher R. Hama** & Luay E. Al- Khurri*** \\
\hline & Abstract
\end{tabular}

Background and objective: Desmoplastic infantile gangliogliomas are rare low grade supratentorial masses that are seen in the pediatric age group. Typically, they involve the superficial cerebral cortex and leptomeninges. Despite the large size of these lesions and some worrisome histological and radiological features, prognosis is generally favorable after gross total resection. To our knowledge, out of about one hundred cases reported worldwide, this is the first Desmoplastic infantile ganglioglioma reported in Kurdistan region-Iraq.

Case presentation: We report a case of Desmoplastic infantile ganglioglioma in a 2-month-old male infant, Computed tomography and magnetic resonance imaging revealed a supratentorial mixed cystic and solid temporal tumor. Near total surgical removal was done. Histopathology revealed features of desmoplastic infantile ganglioglioma, with marked desmoplastic component, glial and neuronal elements. Immunohistochemistry showed positive staining for glial fibrillary acidic protein with areas of synaptophysin positivity.

Conclusion: The diagnosis of Desmoplastic infantile ganglioglioma should be considered in differential diagnosis of tumors with a cystic component and an aggressive appearance. Keywords: Desmoplastic infantile ganglioglioma; histopathology; immunohistochemistry.

\section{Introduction}

Desmoplastic infantile gangliogliomas/ astrocytomas (DIG/DIA) are rare supratentorial tumors of infancy, representing about $15.8 \%$ and $1.25 \%$ of infantile and childhood intracranial tumors respectively. ${ }^{1}$ In the literature, the age ranges from 1 to 24 months, with a male predominance. However, several noninfantile cases have been reported among older children and young adults (5-25 years). ${ }^{2-4}$ Involvement of multiple lobes is common, with a predilection for frontal and parietal lobes, followed by temporal and occipital lobes. ${ }^{5}$ DIG are rarely multiple. ${ }^{6}$ They usually have a solid and a large cystic component (up to as much as $13 \mathrm{~cm}) .^{7}$ DIG without a cystic component have also been described. ${ }^{8}$ Symptomatology usually involves increased head circumference, bulging fontanel, lethargy, hemiparesis and frequent seizures. ${ }^{9}$ Both DIG and DIA share common clinicopathological features and, hence, classified together in the WHO classification of central nervous system tumors. They fall within the category of neuronal and glioneuronal tumors, and both correspond to WHO grade I tumors. ${ }^{10}$ These tumors generally involve superficial cerebral cortex and leptomeninges. Most cases arise in the frontal or parietal lobes, followed by the temporal and, to a lesser extent, the occipital lobes. Grossly, DIG/ DIA tumors usually form a large cystic space, the predominant component, with a smaller solid cortical part of variable size, and often attached to the dura. Microscopically, these tumors are composed of diffuse neoplastic astrocytes

* Department of Pathology, College of Medicine, Hawler Medical University, Erbil, I raq.

** Department of Neurosurgery, Hawler Teaching Hospital, Erbil, I raq.

*** Department of Histopathology, Rizgary Teaching Hospital, Erbil, I raq. 
with a prominent desmoplastic reticulin-rich compact stroma. The only difference between DIG and DIA is the presence of ganglionic cells in the former. ${ }^{11}$ Despite their large size at presentation and some anaplastic cellular features, these tumors mostly behave benignly and generally have an excellent prognosis after total gross resection, with disease-free survival of $8-20$ years. ${ }^{12-14}$ Because of their indolent clinical course, both DIG and DIA are very rarely encountered tumors and may not be detected until they reach gigantic sizes. ${ }^{15}$ In the present study, a two-month-old infant with left temporal desmoplastic infantile ganglioglioma is reported, and the relevant literature was reviewed.

\section{Case report}

In October 2012, a two-month-old male infant presented with increased head circumference and occasional attacks of fits (partial seizures) that were controlled with anti-epileptics. Computerized tomography and magnetic resonance imaging revealed a mass of variable intensity in the left temporal region with hypo and hyperintense areas containing cystic and solid compartments (Figures 1 and 2).

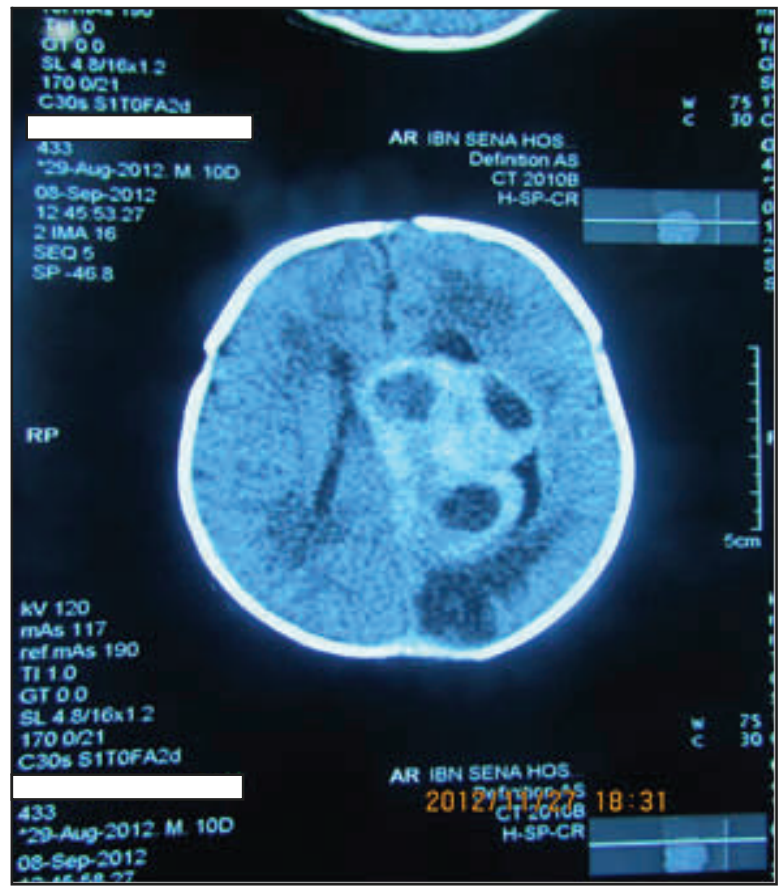

Figure 1: Preoperative CT scan showing a large solid-cystic left temporal lobe tumor.

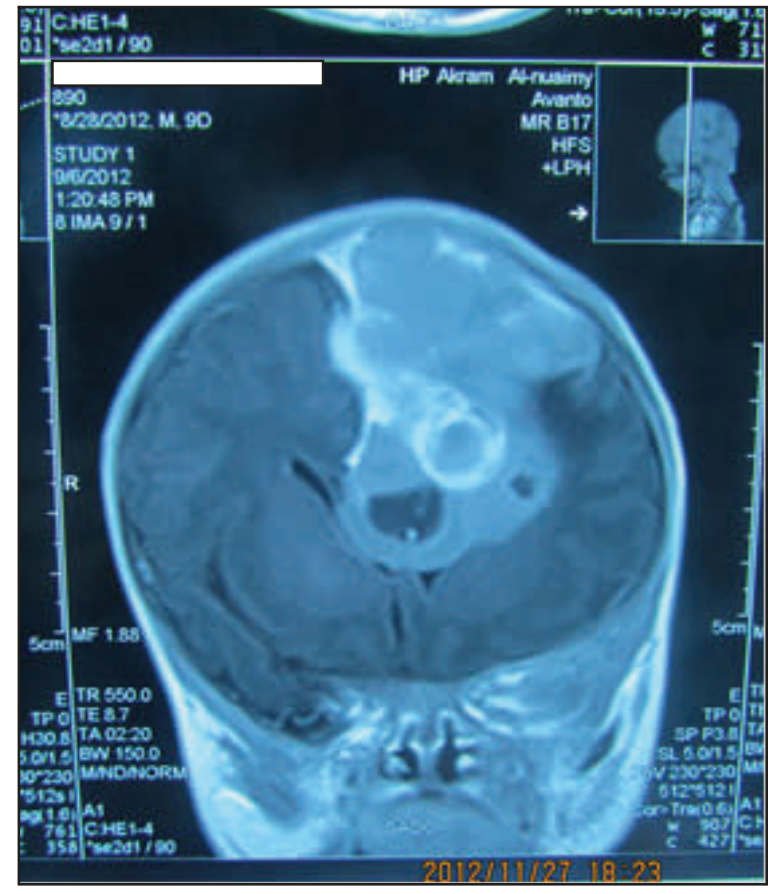

Figure 2: Preoperative MRI showing a huge left temporal lobe tumor with prominent cystic changes. 
Intra-operatively, the mass was moderately vascular, cystic/solid. After being removed, the mass was received as multiple pieces of tissue measuring $60 \times 50 \times 30 \mathrm{~mm}$ in aggregate, firm whitish on cut sections. Histologically, the tumor comprised a marked desmoplastic component with neoplastic astrocytes (Figure 3) and clusters of neuronal elements (Figure 4). Immunohistochemistry (IHC) was

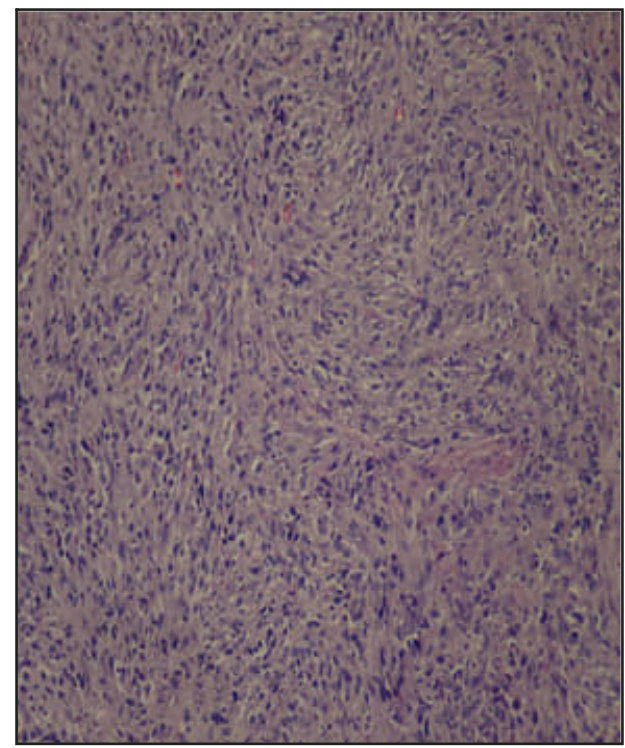

Figure 3: Showing desmoplastic component with neoplastic astrocytes (H\&E x 200)

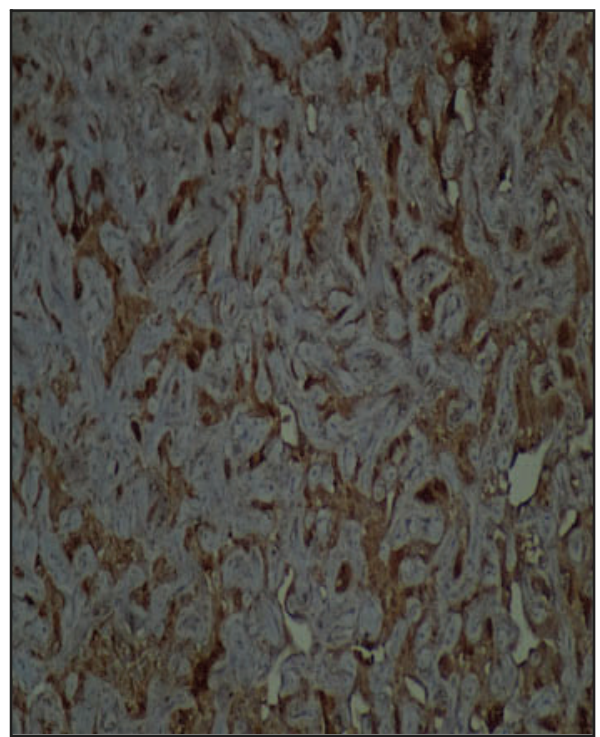

Figure 5: Immunohistochemical staining for glial fibrillary acidic protein. x 200 . performed to confirm the diagnosis. There was diffuse reactivity with glial fibrillary acidic protein (GFAP) (Figure 5) in addition to focal isolated ganglion cells being positive with synaptophysin (Figure 6), and the diagnosis of desmoplastic infantile ganglioglioma was given. One month postoperatively and then after, the patient did well; he is still on anticonvulsant therapy.

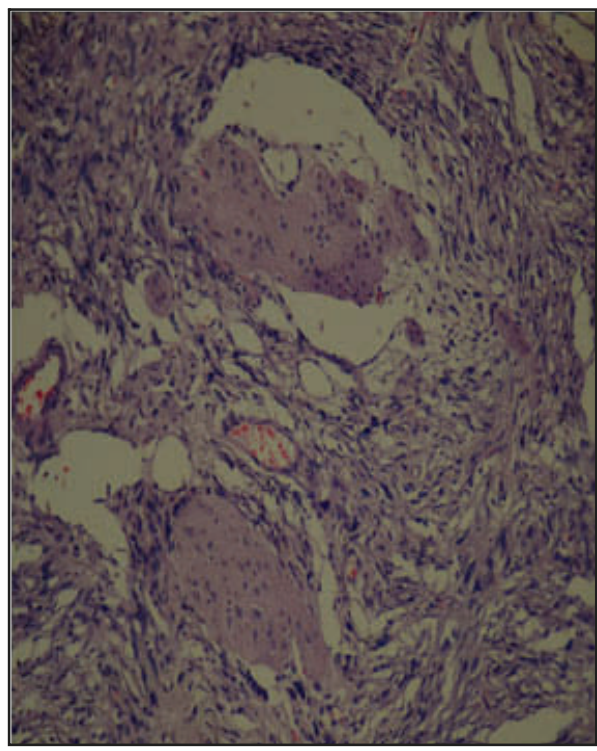

Figure 4: Showing 2 clusters of neuronal elements within the tumor (H\&E x 200).

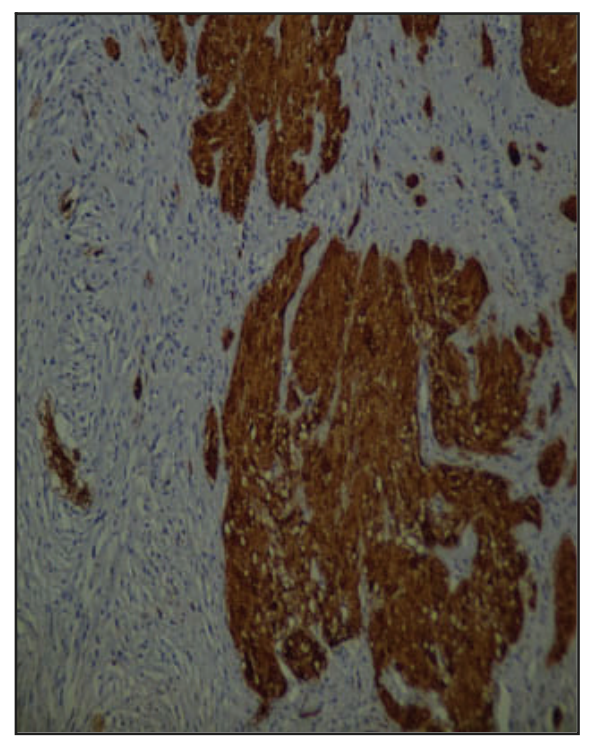

Figure 6: Immunohistochemical expression of synaptophysin. x 200 . 


\section{Discussion}

Together with desmoplastic infantile astrocytoma, both DIG and DIA are grouped as desmoplastic supratentorial neuroepithelial tumors of infancy after being first described by Vanden Berg et al.. at $1987 . .^{13}$ In a large study of 6500 CNS tumors, $22(0.3 \%)$ cases of desmoplastic infantile ganglioglioma were reported; they constituted $1.25 \%$ of all childhood brain tumors. ${ }^{16},{ }^{17}$ However, DIG can no longer be regarded as an exclusively infantile brain tumor as several cases in older age groups (5-25 years) have been reported with a strong male predominance. ${ }^{2,3}$ Supratentorial in location, they commonly involve more than one lobe, preferentially the frontal and parietal lobes. Large lesions involving more than one lobe were seen in $50 \%$ of cases in one series. ${ }^{18}$ Similar to our case, DIG has also been reported in temporal lobe by others. ${ }^{14,19}$ The primitive small cell components expressing both glial and neuronal markers suggest that these are embryonal neoplasms programmed to progressive maturation and eventual growth arrest. ${ }^{20}$ The main histological differential diagnoses are reticulin rich desmoplastic tumors such as pleomorphic xanthoastrocytoma, which can be differentiated by the age of the patient, prominent lipidization of the cells and absence of a neural component. Another differential diagnosis is a ganglioglioma. However, the age of the patient and lack of desmoplasia in ganglioglioma will differentiate it from DIA.6,21 Despite their large size, infiltrating growth pattern, and the worrisome radiological and histological features, DIGs have a favorable prognosis following gross total resection. ${ }^{18}$

\section{Conclusion}

Desmoplastic infantile ganglioglioma are low grade supratentorial masses that are seen in the pediatric age group. They have cystic and solid components and have a heterogeneous density radiologically. These very rarely encountered tumors may not be detected until they reach gigantic sizes. The diagnosis of DIG should be considered in differential diagnosis of tumors with a cystic component and an aggressive appearance.

\section{References}

1. Rout P, Santosh V, Mahadevan A, Kolluri VR, Yasaha TC, Shankar SK. Desmoplastic infantile ganglioglioma: clinicopathological and immunohistochemical study of four cases. Childs Nerv Syst 2002; 18:463-7.

2. Ganesan K, Desai S, Udwadia-Hegde A. Non-infantile variant of desmoplastic ganglioglioma: a report of 2 cases. Pediatr Radiol 2006; 36:541-5.

3. Pommepuy I, Delage-Corre M, Moreau JJ, Labrousse F. A report of a desmoplastic ganglioglioma in a 12-year-old girl with review of the literature. J Neurooncol 2006; 76:271-5.

4. Per $\mathrm{H}$, Kontaş $\mathrm{O}$, Kumandaş S, Kurtsoy A. A report of a desmoplastic non-infantile ganglioglioma in a 6-year-old boy with review of the literature. Neurosurg Rev 2009; 32:369-74.

5. Fan X, Larson TC, Jennings MT, Tulipan NB, Ton SA, Johnson MD. Six month old boy with 2 week history of progressive lethargy. Brain Pathol 2001; 11:265-6.

6. Khaddage $\mathrm{A}$, Chambonniere $\mathrm{ML}$, Morrison $\mathrm{AL}$, Allard D, Dumollard JM, Pasquier B, et al. Desmoplastic infantile ganglioglioma: A rare tumor with an unusual presentation. Ann Diagn Pathol 2004; 8:280-3.

7. Duffner PK, Burger PC, Cohen ME, Sanford RA, Crischer JP. Desmoplastic infantile gangliogliomas: an approach to therapy. Neurosurg 1994; 34:583-9.

8. Sperner J, Gottschalk J, Neumann K, Schör- ner W, Lanksch WR, Scheffner D. Clinical, radiological and histological findings in desmoplastic infantile ganglioglioma. Childs Nerv Syst 1994; 10:458-62.

9. Alexiou GA, Stefanaki K, Sfakianos G, Prodromou N. Desmoplastic Infantile Ganglioglioma. A Report of 2 cases and a review of the Literature. Pediatr Neurosurg 2008; 44:422-5.

10. Brat DJ, Vandenberg SR, Figarella-Branger D, Reuss DE. Desmoplastic infantile astrocytoma and ganglioglioma. World Health Organization Classification of Tumors. Pathology and genetics of tumors of the nervous system. IARC:Lyon; 2016. P.144-6.

11. Burger PC, Scheithauer BW. Tumors of the central nervous system. AFIP atlas of tumor pathology; Fourth series, fascicle. AFIP: Washington D.C: Amer Registry of Pathology; 2008. P. 218-22. 
12. Komori T, Scheithauer BW, Parisi JE, Watterson J, Priest JR. Mixed conventional and desmoplastic infantile ganglioglioma: an autopsied case with 6-year follow up. Mod Pathol 2001; 14:720-6.

13. VandenBerg SR, May EE, Rubeinstein LJ, Herman MM, Perentes E, Vinores SA, et al. Desmoplastic supratentorial neuroepithelial tumors of infancy with divergent differentiation potential ("desmoplastic infantile gangliogliomas"). J Neurosurg 1987; 66:58-71.

14. VandenBerg SR. Desmoplastic infantile ganglioglioma and desmoplastic cerebral astrocytoma of infancy. Brain Pathol 1993; 3:275-81.

15. Avcı E, Öztürk A, Baba F, Torun F, Karabağ H, Yücetaş S. Desmoplastic infantile ganglioglioma: Case report. TJP 2008; 50:495-9.

16. Mallucci C, Lellouch-Tubiana A, Salazar C, Cinalli G, Renier D, Sainte-Rose C, et al. The management of desmoplastic neuroepithelial tumors in childhood. Childs Nerv Syst 2000; 16:8 $-14$.

17. Taratuto AL, Monges J, Lylyk P, Leiguarda R. Superficial cerebral astrocytoma attached to dura. Report of six cases in infants. Cancer 1984; 54:2505-12.

18. Chandrashekhar TN, Mahadevan A, Vani S, Yasha TC, Sampath S, Chandramouli BA, et al. Pathological spectrum of neuronal/glioneuronal tumors from a tertiary referral neurological Institute. Neuropathol 2012; 32:1-12.

19. Setty SN, Miller DC, Camras L, Charbel F, Schmidt ML. Desmoplastic infantile astrocytoma with metastases at presentation. Mod Pathol 1997; 10:945-51.

20. Rutka JT, Giblin JR, Apodaca G, DeArmond SJ, Stern R, Rosenblum ML. Inhibition of growth and induction of differentiation in a malignant human glioma cell line by normal leptomeningeal extracellular matrix proteins. Cancer Res 1987; 47:3515-22.

21. Samarathunga AAS, Fernando C, Fernando J. Desmoplastic infantile astrocytoma; an uncommon pediatric intracranial tumor. JDP 2012; 1:59-61. 